\title{
PEMETAAN DAERAH RAWAN BENCANA TANAH LONGSOR PADA DAS TONDANO BAGIAN HULU SEBAGAI LABORATORIUM ALAM MAHASISWA GEOGRAFI
}

\author{
Denny Maliangkay \\ Program Studi Geografi, Fakultas Ilmu Sosial, Universitas Negeri Manado \\ e-mail: dennymaliangkay@unima.ac.id
}

\begin{abstract}
Landslides are a type of natural disaster that often occurs in Indonesia, especially during the rainy season. The possibility of the frequency of occurrence or occurrence of landslides is higher than other types of disasters. Landslide or often referred to as ground movement is a geological event that occurs because of the movement of rock or soil with various types and types such as falling rocks or large lumps of soil. Although the main cause of this event is gravity which affects a steep slope, but there are also other factors that influence. In order to monitor and observe the phenomenon of landslides, it is necessary to have an analysis and mapping of landslide-prone areas that are able to provide an overview of the condition of existing areas based on the factors causing landslides. In addition, we can also find out the distribution of landslide-prone areas and the main factors causing them so that we can formulate relief efforts. Landslides that occurred in the upper Tondano watershed include small, medium and large size landslides. Landslides that affect the upstream Tondano watershed activities, the morphometry is directly measured in the field. The measured slope condition is the slope of the landslide, not the overall terrain. From the observations made, landslides that occurred in the study area both types of landslides (slides), flow and collapse / tumble (fall), currently all of them totaled 14 points. The dominant type of land slides that occur in the study area is the type of flow.
\end{abstract}

Keywords: Mapping, Landslides

\begin{abstract}
Abstrak: Tanah longsor (landslide) merupakan salah satu jenis bencana alam yang sering terjadi di Indonesia, terutama pada musim hujan. Kemungkinan frekuensi kejadian atau terjadinya longsor lebih tinggi dibandingkan dengan jenis bencana lainnya. Longsor atau sering disebut gerakan tanah adalah suatu peristiwa geologi yang terjadi karena pergerakan masa batuan atau tanah dengan berbagai tipe dan jenis seperti jatuhnya bebatuan atau gumpalan besar tanah. Meskipun penyebab utama kejadian ini adalah gravitasi yang memengaruhi suatu lereng yang curam, namun ada pula faktor-faktor lainnya yang turut berpengaruh. Agar dapat memantau dan mengamati fenomena tanah longsor diperlukan adanya suatu analisa dan pemetaan daerah rawan longsor yang mampu memberikan gambaran kondisi kawasan yang ada berdasarkan faktor-faktor penyebab terjadinya tanah longsor. Selain itu juga kita bisa me-ngetahui sebaran daerah rawan longsor dan faktor utama penyebabnya sehingga kita bisa merumuskan upaya penang-gulangan. Longsor lahan yang terjadi di DAS Tondano bagian hulu meliputi longsoran ukuran kecil, ukuran sedang dan ukuran besar. Longsorlahan yang mempengaruhi aktifitas DAS Tondano bagian hulu, morfometrinya langsung di ukur di lapangan. Kondisi kemiringan lereng yang terukur merupakan kemiringan lereng dari longsoran, bukan merupakan lereng medan secara keseluruhan. Dari hasil pengamatan yang dilakukan, longsorlahan yang terjadi di daerah penelitian baik tipe longsor (slide), aliran (flow) dan runtuhan/jungkiran ( $f a l l)$, saat ini kesemuanya berjumlah 14 titik. Tipe longsor lahan yang dominan terjadi di daerah penelitian adalah tipe aliran (flow).
\end{abstract}

Kata Kunci: Pemetaan, Longsor lahan

\section{PENDAHULUAN}

Indonesia terletak pada pertemuan tiga lempeng dunia, yaitu: lempeng Eurasia, lempeng Pasifik, dan lempeng India-Australia yang bergerak saling menumbuk. Akibat tumbukan antarlempeng tersebut, maka terbentuk daerah penunjaman yang memanjang di sebelah barat Pulau Sumatera, sebelah selatan Pulau Jawa hingga ke Bali dan Kepulauan Nusa Tenggara, sebelah utara Kepulauan Maluku, dan 
sebelah utara Papua. Konsekuensi lain dari tumbukan tersebut adalah terbentuknya palung samudera, lipatan, punggungan dan patahan di busur kepulauan, sebaran gunungapi, dan sebaran sumber gempa bumi. Gunungapi yang ada di Indonesia berjumlah 129 atau 17 persen dari jumlah gunungapi aktif dunia (Zaenudin dalam Y Sartohardi dan E Pratiwi 2014).

Bencana adalah serangkaian peristiwa yang mengancam dan mengganggu kehidupan manusia yang disebabkan oleh faktor alam dan manusia sehingga dapat menyebabkan timbulnya korban jiwa, kerusakan lingkungan, kerugian harta benda dan dampak psikologis. Dalam konteks bencana, dikenal dua buah yaitu (1) bencana alam yang merupakan suatu serangkaian peristiwa bencana yang diebabkan oleh faktor alam yaitu berupa gempa, tsunami, gunung melentus, banjir, kekeringan, angin topan, dan tanah longsor. (2) bencana sosial merupakan suatu bencana yang diakibatkan oleh manusia seperti konflik sosial, penyakit masyarakat, dan terror (Wikippedia 2012). kebakaranhutan. Bencana alam adalah bencana yang diakibatkan oleh peristiwa atau mitigasi yang berbeda-beda sesuai dengan sifat masingmasing bencana alam. Tanah longsor adalah perpindahan material pembentuk lereng berupa batuan, bahan rombakan, tanah, atau material campuran tersebut, bergerak ke bawah atau keluar lereng. Proses terjadinya tanah longsor dapat diterangkan sebagai berikut. Air yang meresap ke dalam tanah akan menambah bobot tanah. Jika air tersebut menembus sampai tanah kedap air yang berperan sebagai bidang gelincir, maka tanah menjadi licin dan tanah pelapukan di atasnya akan bergerak mengikuti lereng dan keluar lereng.

Tanah longsor (landslide) meru-pakan salah satu jenis bencana alam yang sering terjadi di Indonesia, terutama pada musim hujan. Kemungkinan frekuensi kejadian atau kemungkinan terjadinya longsor lebih tinggi dibandingkan dengan jenis bencana lainnya.

Untuk menghindari jatuhnya korban yang lebih besar dan banyak akibat bahaya tanah longsor, diperlukan upaya-upaya yang mengarah kepada tindakan me-minimalisir akibat yang akan ditimbulkan.

Tujuan yang diharapkan dalam pemetaan daerah rawan longsor pada DAS Tondano bagian hulu adalah untuk menetukan lokasilokasi daerah rawan longsor pada DAS Tondano bagian hulu, serta memberikan gambaran kondisi kawasan yang ada berdasarkan faktorfaktor penyebab terjadinya tanah longsor. Selain itu juga kita bisa mengetahui sebaran daerah rawan longsor dan faktor utama penyebabnya sehingga dapat merumuskan upaya penanggulangan.

\section{METODE}

Penelitian ini adalah penelitian survey yang dikaji adalah kondisi fisik lapangan, yang meliputi: 1) Iklim, 2) Kemiringan Lereng, 3) Tutupan Lahan, dan 4) Struktur Geologi.

Metode penelitian menggunakan metode deskriptif kwalitatif dengan pendekatan overley peta untuk menghasilkan peta rawan longsor.

Teknik pengumpulan data dalam penelitian ini di gunakan ada dua jenis data yaitu:

1. Primer, dikumpulkan melalui pengukuran dilapangan seperti kemiringsn lereng, panjang lereng, kedalaman tanah efektif tanah.

2. Sekunder, yang dikumpulkan antara lain: Peta-peta Dasar seperti peta Topografi/ Rupabumi. Geologi, Tutupan lahan, yang didapat pada BAPEDA SULUT. Data Klimatologis diperoleh melalui kantor BMG Kayuwatu Manado.

Analisis Data dilakukan dengan cara scoring atau harkat sebagai berikut:

\section{Lereng}

Pengharkatan kemiringan lereng didasarkan pada konsep bahwa pada dasarnya kemiringan lereng berpengaruh terhadap gaya tarik bumi dan gaya geser sepanjang lereng. Semakin datar lereng, gaya tarik bumi dapat bekerja sepenuhnya, sehingga material lapuk dan lepas tidak akan terjadi pergeseran horizontal, akan tetapi pada lereng miring hingga terjal akan terjadi resultan gaya akibat adanya gaya tarik bumi dan gaya geser. Selain itu kemiringan lereng datar, gerakan air tanah lebih lambat disbanding pada lereng miring.

\section{Penggunaan Lahan}

Penggunaan lahan dimaksudkan berbagai bentuk campur tangan manusia didalam memanfaatkan sumber daya alam guna kesejahteraan manusia. Wujud dan pemanfaatan lahan seperti penterasan, pencangkulan, penanaman kayu pada lereng dengan 
kemiringan tertentu, yang tidak mengikuti aturan konservasi, maka akan menimbulkan masalah baru seperti longsor.

\section{Kerapatan Vegetasi}

Kerapatan vegetasi dilihat dari tingkat kerapatan tanaman dan tajuk daun. Lahan yang tertutup rapat oleh vegetasi, kurang memberikan kesempatan sinar matahari mencapai permukaan tanah sehingga pelapukan fisik terhambat, sedangkan lahan yang tidak tertutup oleh vegetasi akan terjadi kondisi yang berbalikan.

\section{Kondisi Dinding Terjal}

Dinding terjal merupakan salah satu pencerminaan dari jenis batuan penyusun bentuklahan, kondisi stratigrafi batuan penyusun, proses tektonik apakah berupa sesar dan lipatan, atau dapat pula akibat intensitas torehan oleh aliran permukaan, yang terkonsentrasi dalam alur atau lembah sungai, atau juga karena aktifitas manusia. Kaitannya dengan longsorlahan, dinding terjal dalam suatu wilayah akan sangat mendukung terjadinya longsorlahan. Hal ini disebabkan adanya dinding terjal baik sesar, lipatan, penorehan, akan memberikan kesempatan menerima sinar matahari lebih banyak sehingga pelapukan akan lebih intensif.

Empat faktor pemicu longsor lahan tersebut digunakan untuk mengidentifikasi rawan longsor lahan pada DAS tondano bagian hulu.

\section{HASIL DAN PEMBAHASAN}

\section{Kondisi Geografi Daerah Penelitian}

\section{Letak, Batas dan Luas DAS Tondano}

Daerah penelitian terletak antara $1^{\circ} 06^{\prime}$ 15 " - 1 ${ }^{\circ} 12$ ' $15^{\prime \prime}$ "LU dan $124^{\circ} 45^{\prime} 45^{\prime}$ " - 124 $54^{\circ}$ ' 0 " BT. Secara administrasi pemerintahan daerah penelitian terletak di Kabupaten Minahasa Propinsi Sulawesi Utara yang terdiri dari 5 kecamatan, namun tidak semua wilayah kecamatan tersebut yang termasuk daerah penelitian. Cakupan daerah penelitian secara administrasi pemerintah tersebut termasuk wilayah Kecamatan Kakas, Langowan Raya, Tompaso, dan sebagian kecamatan Remboken.

\section{Iklim}

Untuk menggambarkan kondisi iklim digunakan cara rerata hitung setiap unsure iklim, agar informasi yang diperoleh cukup akurat menggambarkan fluktuasi kondisi iklim daerah survey.

\section{a) Curah Hujan}

Data curah hujan rerata bulanan disajikan pada table 4.2. curah hujan rerata bulanan berkisar antara $76-281,3 \mathrm{~mm}$. Temperatur Udara.

Untuk mengetahui besarnya temperature udara di daerah penelitian, maka temperature udara yang tercatat di Stasiun Klimatologi Kawangkoan dikoreksi dengan menggunakan persamaan :

$\mathrm{T}=0.006\left(Z_{1}-Z_{2}\right) \ldots$

(Mock, 1973)

Keterangan :

$\mathrm{T}=$ Beda temperature udara dari ketinggian $Z_{1}$ dan $Z_{2}$

$Z_{1}=$ Ketinggian stasiun Klimatologi $(\mathrm{m})$

$Z_{2}=$ Ketinggian Lokasi Penelitian $(\mathrm{m})$

Tabel.4.1. Temperatur Udara Rerata Bulanan

\begin{tabular}{lllll}
\hline Bulan & Kakas & Langowan & Noongan & Tompaso \\
\hline Januari & 21.9 & 21.6 & 21 & 21.45 \\
Februari & 22.2 & 21.9 & 21.3 & 21.75 \\
Maret & 22.4 & 22.1 & 21.3 & 21.95 \\
April & 22.6 & 22.1 & 21.7 & 22.15 \\
Mei & 23.1 & 22.8 & 22.2 & 22.65 \\
Juni & 22.2 & 21.9 & 21.3 & 21.75 \\
Juli & 22.2 & 21.9 & 21.3 & 21.75 \\
Agustus & 23.3 & 22 & 21.4 & 21.85 \\
September & 22.9 & 22.6 & 22 & 22.45 \\
Oktober & 22.9 & 22.6 & 22 & 22.45 \\
November & 22.8 & 22.5 & 21.9 & 22.35 \\
Desember & 22.3 & 22 & 21.4 & 21.85 \\
\hline
\end{tabular}

Sumber: Badan Meteorologi dan Klimatologi Manado - Hasil Perhitungan.

Untuk menentukan tipe Iklim daerah penelitian digunakan penggolongan tipe iklim menurut Koppen, sedangkan tipe curah hujan didasarkan menurut Schmit dan ferguson.

Tabel 4.2. Penentuan Tipe Iklim Stasiun Penakar Curah Hujan Daerah Penelitian Menurut Koppen

\begin{tabular}{lllll}
\hline $\begin{array}{l}\text { Satasiun } \\
\text { Curah }\end{array}$ & $\begin{array}{l}\text { Temperatur } \\
\text { Udara }\end{array}$ & $\begin{array}{l}\text { Total } \\
\text { Hujan } \\
\text { Bulan } \\
\text { Terdingin } \\
\left({ }^{\circ} \mathrm{C}\right)\end{array}$ & $\begin{array}{l}\text { Temperatur } \\
(\mathrm{mm})\end{array}$ & $\begin{array}{l}\text { Tipe } \\
\text { Udara } \\
\text { Rerata } \\
\text { Tahun } \\
\left({ }^{\circ} \mathrm{C}\right)\end{array}$ \\
\hline Kakas & 21.9 & 1912.5 & 23.57 & $\mathrm{~A}$ \\
Langowan & 21.6 & 2302.6 & 22.18 & $\mathrm{~A}$ \\
Noongan & 21 & 2239.6 & 21.66 & $\mathrm{~A}$ \\
Tompaso & 21.45 & 2245.6 & 22.0 & $\mathrm{~A}$ \\
\hline Sumber: table & 4.1 dan table 4.2. hasil perhitungan &
\end{tabular}


Untuk penggolongan tipe iklim menurut Schmidt dan ferguson yang didasarkan atas nilai $\mathrm{Q}$, yaitu perbandingan antara rata-rata antara bulan kering dan rata-rata bulan basah. Nilai Q dapat diperoleh dengan persamaan.

$\mathrm{Q}=\frac{\text { Jumlah rata-rata bulan kering }}{\text { Jumlah rata-rata bulan basah }}$ x $100 \%$

Secara skematik harga dari Q dalam hubungannya untuk menentukan tipe

Tabel 4.3. Klasifikasi Tipe Iklim Daerah Penelitian Menurut Schmidt dan Ferguson

\begin{tabular}{lllll}
\hline \multirow{2}{*}{$\begin{array}{l}\text { Tama } \\
\text { Tempat }\end{array}$} & \multicolumn{2}{l}{ Rerata Jumlah Bulan } & \multirow{2}{*}{$\begin{array}{l}\text { Nilai } Q \\
(\%)\end{array}$} & Klasifikasi \\
\cline { 2 - 3 } & Basah & Kering & & \\
\hline Kakas & 11 & 0 & 0 & $\mathrm{~A}$ \\
Langowan & 11 & 2 & 0 & $\mathrm{~A}$ \\
Noongan & 12 & 1 & 0 & $\mathrm{~A}$ \\
Tompaso & 12 & 2 & 0 & $\mathrm{~A}$ \\
\hline
\end{tabular}

Sumber : hasil perhitungan

Dari penggolongan data diatas, ternyata semua stasiun termasuk dalam golongan sangat basah (A).

b) Kelembaban Udara

Data kelembaban udara relative di daerah penelitian tidak ada. Untuk itu diambil data kelembaban nisbi dari stasiun Meteorologi dan klimatologi Kayuwatu selama 10 tahun. Besarnya kelembaban udara nisbi rata-rata bulanan dapat dilihat pada table 4.4. berikut ini.

Tabel 4.4. Kelembaban Udara Nisbi Rerata Bulan Daerah Penelitian

\begin{tabular}{ll}
\hline Bulan & Kelembaban udara Nisbi $(\%)$ \\
\hline Januari & 88.70 \\
Februari & 87.72 \\
Maret & 87.00 \\
April & 84.83 \\
Mei & 87.81 \\
Juni & 82.57 \\
Juli & 75.87 \\
Agustus & 64.71 \\
September & 74.60 \\
Oktober & 81.45 \\
November & 87.83 \\
Desember & 87.67 \\
\hline
\end{tabular}

Sumber: Stasiun Meteorologi dan Klimatologi KayuwatuManado.

\section{c) Kecepatan Angin}

Data kecepatan angin daerah penelitian diambil dari data kecepatan angin stasiun terdekat dengat daerah penelitian yaitu stasiun klimatologi Kawangkoan. Kecepatan angin distasiun pengamat Kawangkoan diukur pada ketinggian $2 \mathrm{~m}$, kecepatan angin yang dibutuhkan dalam perhitungan evaporasi adalah pada ketinggian $2 \mathrm{~m}$ sehingga data dari stasiun Klimatologi Kawangkoan dapat langsung digunakan. Besarnya kecepatan angin selama 10 tahun dapat dilihat pada table 4.5

Tabel 4.5. Kecepatan Angin Rerata Bulanan dan Radiasi Matahari Selama 10 Tahun 1984-1994

\begin{tabular}{lll}
\hline Bulan & $\begin{array}{l}\text { Kecepatan Angin } \\
\mathrm{m} / \text { dtk }\end{array}$ & $\begin{array}{l}\text { Radiasi Matahari } \\
\text { Nyata }(\%)\end{array}$ \\
\hline Januari & 1.1 & 51.0 \\
Februari & 1.2 & 51.0 \\
Maret & 1.2 & 46.0 \\
April & 1.0 & 52.0 \\
Mei & 0.9 & 60.0 \\
Juni & 1.4 & 49.0 \\
Juli & 1.8 & 62.0 \\
Agustus & 2.7 & 64.0 \\
September & 1.5 & 63.0 \\
Oktober & 1.2 & 60.0 \\
November & 1.0 & 53.0 \\
Desember & 0.9 & 46.0 \\
\hline Sumber: Stasiun Meteorologi Klimatologi Kayuwatu-Manado.
\end{tabular}

\section{d) Radiasi Matahari}

Radiasi matahari dinyatakan dalam ukuran persentase, yaitu perbandingan jumlah jam penyinaran dengan lamanya pengukuran yang dilakukan. Sama halnya dengan data elemen meteorology lainnya, data radiasi matagari diambil dari Stasiun Tompaso selama 10 tahun. Radiasi matahari terbesar terjadi pada bulan Agustus yaitu sebesar 64,0 \%, sedang radiasi matahari terkecil pada bulan Desember yaitu $46.6 \%$. Untuk

\section{e) Evaporasi}

Besarnya evaporasi (Eo) daerah penelitian dihitung dengan menggunakan metode Penman. Data meteorologi yang dibutuhkan antara lain: temperatur udara, kelembaban udara, kecepatan angin dan radiasi matahari.

Table 4.6 Besarnya Albedo di Daerah Penelitian

\begin{tabular}{|l|l|l|l|l|}
\hline $\begin{array}{l}\text { Penggunaan } \\
\text { Lahan }\end{array}$ & $\begin{array}{l}\text { Luas } \\
(\mathrm{Ha})\end{array}$ & $\begin{array}{l}\text { Luas } \\
(\%)\end{array}$ & $\begin{array}{l}\text { Albedo Tiap } \\
\text { Penggunaan } \\
\text { Lahan }\end{array}$ & $\begin{array}{l}\text { Jumlah } \\
\text { Albedo }\end{array}$ \\
\hline Persawahan & 2501 & 23.334 & 0.1557 & 3.675 \\
\hline $\begin{array}{l}\text { Padang } \\
\text { rumput }\end{array}$ & 325 & 3.032 & 0.26 & 0.778 \\
\hline Pekarangan & 814.7 & 7.601 & 0.1825 & 1.387 \\
\hline Tegalan & 3390.8 & 31.640 & 0.193 & 6.106 \\
\hline Hutan & 3686.5 & 34.400 & 0.095 & 3.268 \\
\hline Jumlah & 10718 & 100 & & 15.214 \\
\hline
\end{tabular}

Sumber: hasil perhitungan 


\section{Topografi}

Keadaan topografi daerah penelitian bervariasi dari datar hingga terjal (kemiringan lereng $0-8 \%$ ) seluas $5 \%$ dari luas daerah penelitian, topografi berombak hingga bergelombang (kemiringan lereng >8 - 15\%) dengan luas $68 \%$ dari luas daerah penelitian, topografi bergelombang hingga berbukit (kemiringan lereng $>15-25 \%$ ) seluas $16 \%$ dari luas daerah penelitian, dan topografi berbukit dengan lereng terjal ( kemiringan lereng $>25-$ $40 \%$ ) dengan luas $11 \%$ dari luas daerah penelitian.

Iklim berpengaruh pada longsorlahan khususnya curah hujan yang mana merupakan salah satu faktor pemicu terjadinya longsorlahan

\section{Vegetasi}

Vegetasi (tumbuh - tumbuhan) penutup lahan memiliki hubungan dengan gejala longsorlahan hal tersebut disebabkan karena vegetasi cukup berpengaruh terhadap lajunya air permukaan maupun akarnya yang berfungsi sebagai pengikat tanah hasil pelapukan, sehingga akan menghambat atau bahkan menahan proses erosi.

Selain kegunaan tersebut, vegetasi juga mempercepat proses terbentuknya tubuh tanah, hal tersebut merupakan pengaruh negatif yang tidak bias dihindari lagi terhadap kestabilan lahan.

Di daerah penelitian hal ini terlihat bahwa longsorlahan banyak terjadi pada daerah daerah yang gundul atau yang sudah jarang ditumbuhi pepohonan dan rerumputan.

\section{Kondisi Geomorfologi}

Geomorfologi daerah penelitian terbentuk oleh proses vulkanik yang mana sangat dipengaruhi oleh keberadaan Gunungapi Soputan, dan dikelompokkan dalam tiga (3) satuan bentuklahan yakni Lereng tengah gunungapi, Lereng tengah gunungapi kuat, dan Lereng bawah gunungapi terdenudasi.

\section{Penggunaan Lahan}

Penggunaan lahan di daerah penelitian dapat dikelompokan dalam lima (5) kelompok utama yakni permukiman, perkebunan, persawahan, tegalan, dan hutan.

Permukiman yang terdapat pada daerah penelitian merupakan wilayah yang dimanfaatkan oleh warga setempat sebagai tempat bermukim yang mencakup tempat tinggal penduduk beserta lahan pekarangannya, persekolahan, perkantoran, sekolah, puskesmas, rumah makan, rumah ibadah, penginapan, warung, dan pasar. Permukiman di daerah penelitian menempati wilayah - wilayah dengan kemiringan lereng datar hingga miring. Dan khususnya penduduk yang menempati wilayah wilayah dengan kemiringan lereng landai hingga miring, mengharuskan penduduk membuat bidang datar dengan cara memotong lereng perbukitan sebelum membangun tempat kediaman.

Perkebunan di daerah penelitian mencakup perkebunan cengkih, perkebunan kelapa, perkebunan campuran cengki kelapa dan pisang. Perkebunan - perkebunan tersebut terdapat pada bentuklahan dengan kemiringan lereng landai hingga terjal. Hutan yang terdapat di daerah penelitian terdiri dari hutan sejenis dan hutan tak sejenis yakni campuran hutan dan semak. Hutan sejenis berupa hutan cemara, hutan lantoro, dan hutan jati yang hanya terdapat pada bentuklahan denudasional terkikis kuat dengan kemiringan lereng terjal, sedangkan hutan tak sejenis terdapat pada semua bentuklahan dengan kemiringan lereng hingga terjal.

\section{Geologi}

Berdasarkan hasil pengamatan lapangan, kondisi geologi daerah penelitian dideskripsikan berdasarkan peta geologi lembar Manado skala 1:250.000 (Effendi, 1976) Bagian hulu DAS Tondano tersusun oleh satuan batuan sebagai berikut:

a. Batuan gunungapi muda $(\mathrm{Qv})$, yang terdiri dari lava, bom, lapilli dan abu: membentuk gunungapi muda, antara lain Gunung Soputan, Gunung Mahawu, Gunung Lokon, Gunung Gunung Kawatak, yang sebagian masih aktif. Lava yang dikeluarkan oleh Gunung Soputan dan Gunung Lokon terutama adalah basal, sedangkan Gunung Mahawu dan Gunung Tangkoko adalah andesit.

b. Tufa Tondano (Qtv) yang terdiri dari klastika gunungapi kasar yang terutama bersifat andesit, tersusun daripada komponen menyudut hingga menyudut tanggung, tercirikan oleh banyak pecahan batu apung seperti tufa, tufa laipili dan, breksi. 
Berdasarkan satuan geologi penyusun, maka daerah penelitian hanya tersusun oleh 2 kelompok struktur geologi yaitu Qv dan Qtv serta stratigrafi batuan yang berumur kuarter.

\section{Longsor Lahan yang terjadi di DAS Tondano Bagian Hulu}

Longsorlahan yang terjadi di DAS Tondano bagian hulu meliputi longsoran ukuran kecil, ukuran sedang dan ukuran besar. Longsorlahan yang mempengaruhi aktifitas DAS Tondano bagian hulu, morfometrinya langsung di ukur di lapangan. Hasil pengukuran morfometri longsor lahan berdasarkan data di lapangan dapat dilihat pada Tabel. 4.7.

Tabel. 4.7 Kondisi Longsor Lahan di DAS Tondano Bagian Hulu

\begin{tabular}{|c|c|c|c|c|c|c|c|c|c|}
\hline \multirow[t]{2}{*}{ No } & \multirow{2}{*}{$\begin{array}{l}\text { Titik } \\
\text { Longsor } \\
\text { lahan }\end{array}$} & \multirow{2}{*}{$\begin{array}{l}\text { Tipe } \\
\text { Longsor- } \\
\text { lahan }\end{array}$} & \multicolumn{2}{|l|}{ Koordinat } & \multicolumn{2}{|c|}{$\begin{array}{l}\text { Kondisi } \\
\text { Longsorlahan }\end{array}$} & \multicolumn{3}{|c|}{ Kondisi Daerah Peneltian } \\
\hline & & & Lintang & Bujur & $\begin{array}{l}\text { Panjang } \\
(\mathrm{m})\end{array}$ & $\begin{array}{l}\text { Lebar } \\
(m)\end{array}$ & $\begin{array}{l}\text { Kemiringan } \\
\text { Lereng }\end{array}$ & $\begin{array}{l}\text { Penggunaan } \\
\text { Lahan }\end{array}$ & $\begin{array}{l}\text { Kerapatan \& } \\
\text { Jenis Vegetasi }\end{array}$ \\
\hline 1. & 1 & Aliran & 01.23 .19 & 124.41 .11 & 4,5 & 3 & $56 \%$ & Tegalan & $\begin{array}{l}\text { Jarang, Pepaya, } \\
\text { Pisang }\end{array}$ \\
\hline 2. & 2 & Aliran & 01.23 .18 & 124.41 .13 & 6 & 3,5 & $37 \%$ & Kebun & Jarang, Cengkeh \\
\hline 3. & 3 & Aliran & 01.23 .16 & 124.41 .17 & 35 & 27,5 & $43 \%$ & Hutan & $\begin{array}{l}\text { Rapat, Semak, } \\
\text { Alang-Alang, }\end{array}$ \\
\hline 4. & 4 & Longsor & 01.23 .15 & 124.41 .18 & 1 & 2 & $24 \%$ & Kebun & Rapat, Semak \\
\hline 5. & 5 & Runtuhan & 01.23 .17 & 124.41 .21 & 6 & 13 & $75 \%$ & Kebun & $\begin{array}{l}\text { Jarang, Semak, } \\
\text { Bambu }\end{array}$ \\
\hline 6. & 6 & Runtuhan & 01.23 .08 & 124.41 .51 & 12 & 6 & $70 \%$ & Kebun & $\begin{array}{l}\text { Jarang, Cengkeh, } \\
\text { Rumput }\end{array}$ \\
\hline 7. & 7 & Runtuhan & 01.23 .01 & 124.42 .00 & 19 & 7 & $72 \%$ & Hutan & $\begin{array}{l}\text { Jarang, Alang- } \\
\text { Alang }\end{array}$ \\
\hline 8. & 8 & Runtuhan & 01.20 .34 & 124.43 .40 & 6 & 13 & $42 \%$ & Kebun & Jarang, Kelapa \\
\hline 9. & 9 & Runtuhan & 01.20 .33 & 124.43 .42 & 10,5 & 14,9 & $63 \%$ & Hutan & $\begin{array}{l}\text { Sangat } \\
\text { Jarang,Semak }\end{array}$ \\
\hline 10. & 10 & Aliran & 01.20 .18 & 124.43 .32 & 36 & 11 & $39 \%$ & Kebun & $\begin{array}{l}\text { Jarang, Kelapa, } \\
\text { Alang-Alang }\end{array}$ \\
\hline 11. & 11 & Longsor & 01.20 .22 & 124.43 .30 & 1 & 2,5 & $27 \%$ & Kebun & $\begin{array}{l}\text { Sedang, } \\
\text { Cengkeh, }\end{array}$ \\
\hline 12. & 12 & Aliran & 01.20 .27 & 124.43 .25 & 14 & 7 & $48 \%$ & Hutan & $\begin{array}{l}\text { Jarang, Mahoni, } \\
\text { Semak }\end{array}$ \\
\hline 13. & 13 & Aliran & 01.18 .36 & 124.44 .56 & 21,5 & 18 & $56 \%$ & Tegalan & $\begin{array}{l}\text { Sedang, Pisang, } \\
\text { Rumput, Jagung }\end{array}$ \\
\hline 14. & 14 & Aliran & 01.18 .40 & 124.44 .40 & 7 & 6 & $23 \%$ & Kebun & $\begin{array}{l}\text { Sedang, Pohon } \\
\text { Kecil, Pepaya }\end{array}$ \\
\hline
\end{tabular}

Sumber: Data primer penelitian, 2015

\section{KESIMPULAN}

Berdasarkan hasil penelitian yang telah diperoleh sesuai dengan batas-batas penelitian, maka dapat disimpulkan sebagai berikut:

1) Teridentifikasi tiga tipe longsorlahan yang terjadi di DAS Tondano bagian hulu yang meliputi; runtuhan (fall), longsor (slide), dan aliran (flow). Dari ketiga tipe longsorlahan jumlah tipe longsorlahan yang paling banyak terjadi adalah rayapan (flow).

2) Berdasarkan parameter yang dikaji terdapat pengaruh yang cukup signifikan terhadap kejadian longsorlahan pada setiap titik. Curah hujan yang cukup tinggi, kemiringan lereng yang berkisar antara agak curam sampai sangat curam, serta penggunaan lahan beserta kerapatan dan Tipe longsorlahan yang terjadi

Berdasarkan pengamatan di daerah penelitian terdapat tiga tipe longsorlahan yaitu:

1. Runtuhan/Jatuhan (fall) merupakan gerakan material secara tegak akibat pengaruh gaya berat, umumnya terjadi pada tebing curam, material yang bergerak jatuh bebas, menggelundung atau memantul pada tebing. Tipe runtuhan batuan (rock fall) menghasilkan material berupa batu yang berukuran kecil, sedang, 
dan besar. Batu-batu besar yang jatuh dapat menyebabkan kerusakan yang parah.

2. Longsor (slide) merupakan gerakan meluncur atau jatuhan dari satu atau sekelompok massa tanah dan batuan menuruni lereng karena pengaruh gravitasi juga oleh adanya bidang perlapisan, retakan, dan patahan. Tipe longsor (slide) ini bisa diidentifikasi

3. Aliran (Flow) merupakan tipe longsorlahan yang terjadi ketika massa tanah bergerak didorong oleh air. Kecepatan aliran tergantung pada kemiringan lereng, volume dan tekanan air, dan jenis materialnya. Gerakannya terjadi di sepanjang lembah dan mampu mencapai ratusan meter jauhnya. Di beberapa tempat bisa sampai ribuan meter seperti di daerah aliran sungai disekitar gunungapi. Aliran tanah ini dapat menelan korban cukup banyak. Tipe longsor lahan yang terjadi di daerah penelitian alirannya hanya puluhan meter jauhnya dan untungnya tidak menelan korban. Material yang dibawa hanya berupa tanah, sehingga tipe ini dapat diklasifikasikan ke dalam tipe Debris Flow atau aliran bahan rombakan tanah.

3) Longsorlahan berdasarkan variabel penelitian

Variabel penelitian dalam hal ini yang menjadi parameter dalam mengidentifikasi titik rawan longsorlahan terdiri atas curah hujan, kemiringan lereng, dan penggunaan lahan.

1) Curah hujan

Longsorlahan yang terjadi di daerah penelitian salah satu penyebab yaitu curah hujan. Hal tersebut menjadikan daerah ini memiliki ketersediaan air sangat melimpah namun hal ini juga menyebabkan terjadinya longsorlahan di beberapa titik pada daerah penelitian.

Intensitas curah hujan yang sangat tinggi dengan durasi yang cukup lama memicu sejumlah titik mengalami longsorlahan. Apalagi di beberapa titik memiliki kondisi air tanah yang cukup besar. Air tanah ini terdapat pada formasi geologi yang permeabelnya tidak mampu menyimpan dan memindah air dalam jumlah cukup besar. Sehingga menyebabkan simpanan air tersebut meluap dan mengalir ke permukaan tanah Selain itu di beberapa titik pada daerah penelitian hujan yang jatuh ke permukaan tanah tidak terhalang oleh pepohonan dan tertampung sehingga pada saat curah hujan semakin tinggi maka terjadilah longsorlahan dengan tipe yang berbeda-beda.

2) Kemiringan lereng jenis vegetasi yang kurang baik menjadi penyebab terjadinya longsorlahan pada setiap titik longsoran di daerah penelitian.

3) Berdasarkan tingkat kerawanan longsor lahan daerah penelitian dibagi atas empat

4) Zona rawan terhadap lonsorlahan meliputi;

a. Zona rawan longsorlahan sangat rendah;

b. Zona rawan longsorlahan rendah ;

c. Zona rawan longsorlahan menengah dan;

d. Zona rawan longsorlahan tinggi.

Interval kemiringan lereng dari setiap titik longsorlahan berada pada $23 \%-75 \%$, sehingga dapat diketahui bahwa dari setiap titik longsoran berada pada zona rawan longsorlahan menengah sampai zona rawan longsorlahan tinggi.

\section{DAFTAR PUSTAKA}

Aep S. Hamidin, 2013. Ancaman Bawah Laut Fakta dan Penemuan Gunung Bawah Laut Indonesia. Cakrawala Yogyakarta.

Asri Pratiwi dkk, 2011. Fenomena Alam Paling Spetakuler. Jogja Great Publisher

Djauhari Noor. 2006. Geologi Lingkungan. Graha Ilmu Yogyakarta

2001. Geologi untuk Perencanaan. Graha Ilmu Yokyakarta

Junun Sartohadi Dan Elok Surya Pratiwi. 2014. Bunga Rampai Penelitian Pengelolaan Bencana

Jim Pipe. 2008. Planet Eart Weather and Climate. Copyright tiktock. First published in Great Britain

Kegunungapian Kelud pada Periode Krisis Erupsi 2014. Pustaka Pelajar. Yogyakarta.

G. Moch. Munir, 1996. Geologi dan Mineralogi Tanah. Pustaka Jaya. Jakarta

Hendra Wisesa. 2011. Buku Pinter Bumi Ensiklopedi Lengkap. Harmoni Jogyaakarta

M. Lange dkk, 1991. Geologi Umum. Gaya Media Pratama Jakarta

Sampaguita Syafrezani, 2010. Tanggap Bencana Alam Gempa Bumi. Angkasa Bandung

Singgih Sastradihardja, 2010. Tangap Bencana Alam Gunung Berapi. Angkas Bandung 
Sutoto, 2013. Geologi Dasar. Ombak Yogyakarta.

Trija Fayeldi dan Syerif Nurhakim, 2012 Cuaca dan Iklim Fenomena Perubahan Alam Global dari Kutup Hingga Khatulistiwa. Bestari Kids. Rawamagun Jakarta Timur 